\title{
Prognostic Importance of Ki-67 Labeling Index in Grade II Glial Tumors
}

\section{Gül KANYILMAZ, ${ }^{1} \odot$ Hatice ÖNDER, ${ }^{2} \odot$ Meryem AKTAN, ${ }^{1} \odot$ Mehmet KOÇ, ${ }^{1} \odot$ Hüseyin BORA, ${ }^{3}$}

\section{Eray KARAHACIOĞLU, ${ }^{3} \odot$ Haldun Şükrü ERKAL 4 ๑ Eda YiRMIBESOĞLU ERKAL}

Department of Radiation Oncology, Necmettin Erbakan University Meram Medical Faculty, Konya-Turkey 2Department of Radiation Oncology, Bülent Ecevit University School of Medicine, Zonguldak-Turkey 3Department of Radiation Oncology, Gazi University School of Medicine, Ankara-Turkey ${ }^{4}$ Department of Radiation Oncology, Sakarya University School of Medicine, Sakarya-Turkey
${ }^{5}$ Department of Radiation Oncology, Kocaeli University School of Medicine, Kocaeli-Turkey

\section{OBJECTIVE}

To date, several methods have been identified for predicting the prognostic subgroups of grade II gliomas: however these methods have some limitations in predicting survival. So, we aimed to determine the predictive role of Ki-67 labeling index (LI) on survival.

\section{METHODS}

Between 1995 and 2014, patients with grade II gliomas were retrospectively analyzed. All patients re-

\section{RESULTS}

This study included 78 patients with median 44 (range, 6-137) months follow-up. Patients aged $\geq 40$ year had a poorer overall survival (OS) than those aged $<40$ years $(\mathrm{p}=0.04)$. Patients with gross total resection/ subtotal resection had a longer OS than those with biopsy/partial resection ( $\mathrm{p}=0.001)$. If the disease had recurrence or progression during the follow-up period, the patients had a poorer OS $(\mathrm{p}=0.01)$. Patients with a Ki-67 LI $\geq 4 \%$ had a poorer OS than those with Ki-67 LI $<4 \%$ ( $\mathrm{p}=0.001)$. The extent of resection, recurrence, or progression, and Ki- $67 \geq 4 \%$ were the independent prognostic factors for OS.

\section{CONCLUSION}

In our opinion, Ki-67 LI is an important prognostic factor for grade II gliomas, but it cannot be used as a diagnostic measure alone. It must be used in combination with the other prognostic factors.

Keywords: Grade II glial tumors; Ki-67 labeling index; Prognostic factors; Radiotherapy; Survival.

Copyright $\odot$ 2018, Turkish Society for Radiation Oncology

\section{Introduction}

Low-grade gliomas (LGGs) account for $15 \%-20 \%$ of all primary brain tumors. LGGs may eventually undergo malignant transformation and progress into high-grade gliomas, resulting in high morbidity and mortality GGs harbor a heterogeneous spectrum of histopatho- logical subtypes, and therefore, optimal treatment is controversial.[1-3] To date, several methods for predicting the prognostic subgroups of LGGs have been identified. These methods evaluated clinical variables $[4,5]$ tumor grading [6], and histopathologic classification. [6] Tumor grading and histopathologic classification are subjective methods since they are based on light micro-

\section{Received: March 05, 2018
Accepted: March 05, 2018 \\ Accepted: March 05, 2018
Online: May 31,2018}

Accessible online at:
Dr. Gül KANYILMAZ

Meram Tip Fakültesi,

Radyasyon Onkoloj;

Konya-Turkey scopic techniques.[7] Besides, almost all methods for predicting the prognostic subgroups of LGGs have some limitations in predicting survival. In this regard, there is a need to develop new prognostic markers with the aim of predicting tumor behavior and prognosis.

Proliferative phases of the cell cycle are composed of G1-phase, S-phase, G2-phase, and M-phase. The Ki-67 monoclonal antibody is detected during all these prolifrative phases of the cell cycle, but absent in the resting cells (G0-phase) [8] Ki-67 positive cells can be inesting cells (G0-phase).[8] chemically imaged, identified, counted, and labeled as a percentage of total cells. This relationship is named the "labeling index" (LI) or the "proliferation index." Since its discovery in the 1980s, there has been an increasing interest in the role of Ki-67 index as a proliferation marker in cancer, and it has been shown to be clinically useful in distinguishing the tumor behavior and correlates well with histologic grade, mitotic activity, and other proliferation markers. [9-18] In this current study we imed to investigete the posible prognostic relationsip bi-67 LI and possivive poutcon of a dult between Ki-67 LI and he survival outcomes of adult paglial tumors who were treated with radiotherapy (RT).

Materials and Methods

2.1. Patient population

Between 1995 and 2014, adult patients with grade II glial tumors who had been irradiated at our departments cere evaluated in this retrospec were evalo in this retrosective sty. grade II glial tumors, be over 16 years of age, and have heir paraffin-embedded tumor tissue blocks available. The study was approved by the review boards and conducted according to the ethical principles of the declaration of Helsinki.

\section{Radiotherapy}

Radiotherapy is used in patients with tumors that cannot be totally removed or in patients with high-risk features. [19] High-risk factors were defined by Pignatti and colleagues; these factors were identified as age $\geq 40$ years, colleagues; these factors were identified as age $\geq 40$ years,
tumor size $\geq 6 \mathrm{~cm}$, tumor crossing the midline, preoperatumor size $\geq 6 \mathrm{~cm}$, tumor crossing the midline, preopera-
tive neurologic deficit existence, and astrocytoma histoltive neurologic deficit existence, and astrocytoma histol-
ogy subtype. The presence of $\geq 3$ of the above-mentioned factors is defined as high risk. [20] Postoperative early RT is frequently used in patients with WHO grade II glial tumors that cannot be totally resected or in patients who are suspected to have high-risk features, whereas delayed RT is frequently used in patients with recurrence or progression. The patients received RT with 1.8-2 Gy fractions 5 days a week for a total dose of 50-66 (mean, $54 \mathrm{~Gy}$ ) Gy to the tumor (with $1-2 \mathrm{~cm}$ margins).

\subsection{Histopathology and Ki-67 expression}

Two experienced neuropathologist retrospectively redefined all tumors based on the 2007 WHO classification system for brain tumors.[21] If the neuropathologist did not agree on the definition of the pathologica status, a third neuropathologist re-evaluated the tumor tissue. Immunohistochemical staining for Ki-67 was perform on forman performed tis- pections. Proliferation ind pxes were reported as the percentage of tumor cell nuclei labeled with the Ki-6 monoclonal antibody in paraffin-embedded specimen For each patient, areas with the highest number of positively stained tumor nuclei were chosen for reporting.

2.4. Clinical evaluation and follow-up

Following RT, patients were followed up every 3 month for 2 years, every 6 months for 3-5 years, and annually thereafter.

\subsection{Statistical analysis}

Statistical analyses were performed using Statistical Package for Social Sciences software, v 13.0 (SPSS, Chicago, IL, USA). Patient, disease, and treatment characteristics were analyzed using descriptive statistics. The median value, mean value, proportion value, ranges, and standard deviation values were reported. Categorical variables were compared using Pearsons Chi-square test, and continus varables were comtest and ANOVA

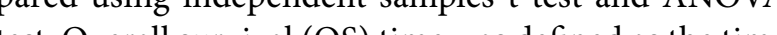
from diagnosis to the date of the death or last follow-up Progression-free survival (PFS) was defined as the time from diagnosis to the date of documented progression or recurrence. Survival analyses were performed using the Kaplan-Meier method, and subgroups were compared using the two-sided log rank test. Cox proportional hazard regression analysis was used for the esti-

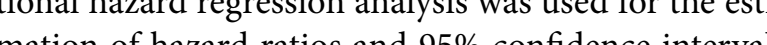
intervals Cls). Varables with statistical significance $(\mathrm{p} \leq 0.05)$ in univariate analysis were included as covariates in multivariate analysis. A two-sided $\mathrm{p}$-value of $\leq 0.05$ was considered to be statistically significant.

Results

3.1. Patient and tumor characteristics

This study included 78 patients with grade II glial tumors with a median follow-up of 44 (range, 6-137 months) 


\begin{tabular}{|c|c|c|}
\hline Variables & $\begin{array}{l}\text { No. of patients } \\
\text { (total:78) }\end{array}$ & \\
\hline \multicolumn{3}{|l|}{ Age (years) } \\
\hline Median & 38 & \\
\hline Range & $16-62$ & \\
\hline$<40$ & 44 & 56 \\
\hline$\geq 40$ & 34 & \\
\hline \multicolumn{3}{|l|}{ Gender } \\
\hline Male & 43 & \\
\hline Female & 35 & 45 \\
\hline \multicolumn{3}{|l|}{ Surgery type } \\
\hline Biopsy or parsial resection & 18 & \\
\hline Subtotal resection & 35 & 45 \\
\hline Gross total resection & 25 & 32 \\
\hline \multicolumn{3}{|l|}{ Histopathology } \\
\hline Grade II astrositoma & 59 & 76 \\
\hline Grade II oligodendroglioma & 15 & 19 \\
\hline Grade II oligoastrositoma & 4 & 5 \\
\hline \multicolumn{3}{|c|}{ Neurologic deficit existence at diagnosis } \\
\hline No & 43 & 55 \\
\hline Yes & 35 & 45 \\
\hline \multicolumn{3}{|l|}{ Seizures at diagnosis } \\
\hline No & 44 & 56 \\
\hline Yes & 34 & \\
\hline \multicolumn{3}{|l|}{ Timing of RT } \\
\hline Early & 51 & 65 \\
\hline Delayed & 27 & 35 \\
\hline \multicolumn{3}{|l|}{ Radiation dose (Gy) } \\
\hline Median & 54 & \\
\hline Range & $50-66$ & \\
\hline \multicolumn{3}{|l|}{ Chemotherapy } \\
\hline No & 69 & 88 \\
\hline Yes & 9 & 12 \\
\hline \multicolumn{3}{|l|}{ Ki-67 index (\%) } \\
\hline Median & 1.5 & \\
\hline Range & $0-40$ & \\
\hline$<4$ & 67 & 86 \\
\hline$\geq 4$ & 11 & 14 \\
\hline
\end{tabular}

months. Of these patients, 59 had been diagnosed with astrocytomas, 15 with oligodendrogliomas, and four with oligoastrocytomas. Patients, tumor, and treatment characteristics are summarized in Table 1.

\subsection{Treatment characteristics}

Surgery was the initial treatment approach for all patients. Gross total resection (GTR) was performed in 25 patients (32\%), subtotal resection (STR) in $35(45 \%)$, partial resection (PR) in six (8\%), and only biopsy (Bx) in $12(15 \%)$. Postoperatively, 51 patients $(65 \%)$ received adjuvant early RT, while 27 patients (35\%) received ad-

\begin{tabular}{|c|c|c|c|}
\hline \multirow{2}{*}{$\begin{array}{ll}\text { Table } 2 \text { U } & \text { a } \\
\text { Variables }\end{array}$} & \multicolumn{3}{|c|}{$\begin{array}{l}\text { Univariate cox proportional hazard regression } \\
\text { analysis related with OS }\end{array}$} \\
\hline & HR & $95 \% \mathrm{Cl}$ & P-value \\
\hline \multicolumn{4}{|l|}{ Age } \\
\hline$<40$ years & 1 & & \\
\hline$\geq 40$ years & 2.34 & $0.98-5.59$ & 0.056 \\
\hline \multicolumn{4}{|c|}{ Extent of removal at diagnosis } \\
\hline GTR or STR & 1 & & \\
\hline Bx or PR & 4.81 & $1.67-13.87$ & $0.004^{*}$ \\
\hline \multicolumn{4}{|c|}{ Recurrence or progression } \\
\hline No & 1 & & \\
\hline Yes & 5.56 & $1.29-10.23$ & $0.02^{*}$ \\
\hline \multicolumn{4}{|c|}{ Diagnose with biopsy only } \\
\hline No & 1 & & \\
\hline Yes & 4.96 & $1.67-14.68$ & $0.004^{*}$ \\
\hline \multicolumn{4}{|l|}{ Ki-67 index } \\
\hline$<4 \%$ & 1 & & \\
\hline$\geq 4 \%$ & 4.49 & $1.76-11.47$ & $0.002^{*}$ \\
\hline
\end{tabular}

Abbreviations: OS, overall survival; $G \mathrm{GR}$, gross total resection; $\mathrm{STR}$, subtotal
resection: PR, , Oartial resection; Bx, biopsy.
$*$ Statistically significant.

juvant delayed RT. The median radiation dose was 54 (range, 50-66) Gy.

\subsection{Ki-67 status}

Jaros et al. reported that the heterogeneity in Ki-67 L was around $20 \%$ astrositomas so that the average values of Ki-67 LI represent the proliferative potential of the tumor more than the maximal Ki-67 value.[22] Otherwise, Fisher et al. found that the average Ki-67 value was much more associated with survival than the maxim value of Ki-67.[23] For this reason, the average Ki-67 value of Ki-67.[23] For this reason, the average Ki-67 value was used for the analysis. Seventy-two patien $(92 \%)$ were Ki-67 positive (i.e., the percentage of Ki-6 staining cells was $>0$ ). The median Ki-67 LI value wa $1.5 \%$ (range, $0-40$ ). The majority of patients $(51 \%)$ had a Ki-67 LI value of $\leq 2 \%$. Eleven patients (14\%) had a Ki$67 \mathrm{LI}$ value of $\geq 4 \%$ and eight ( $10 \%$ ) had a Ki-67 LI value of $\geq 5 \%$. Only one patient had a Ki- 67 LI value of $\geq 10 \%$. Survival analyses were performed using the KaplanMeier method at various cutoff points for average Ki-67 value at $1 \%$ intervals between age Ki-67 LI value of $\geq 4 \%$ was associated with OS.

\subsection{Survival analysis}

The median follow-up time was 44 (range, 6-137) months. Fifty-six patients (72\%) were alive and 20 of them had a disease when the survival analysis was performed. The mean OS was 88 (range, 73-102) months.

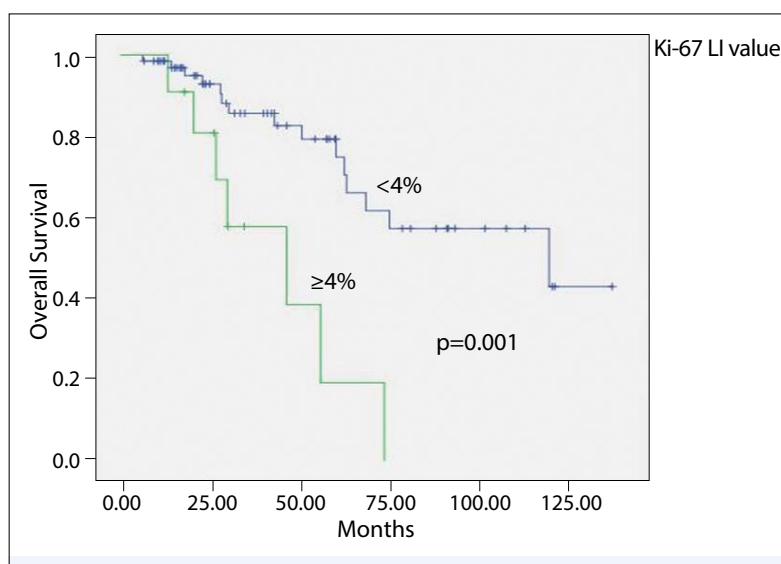

Fig. 1. Overall survival according to the Ki-67 LI value.

$40 \%$, respectively. The extent of resection, recurrence, or progression and average Ki-67 LI value were the significant prognostic factors for OS. A trend of higher survival was found in patients aged $<40$ years. The results of univariate analysis for OS are summarized in sults of
Table 2 .

Patients with a Ki-67 LI value of $\geq 4 \%$ had a poorer OS than patients with a Ki-67 LI value of $<4 \%$ $(\mathrm{p}=0.001)$. The mean OS was 96 months for patients with a Ki-67 LI value of $<4 \%$ versus 43 months for the patients with a Ki-67 LI value of $\geq 4 \%$ (Fig 1 ). The mean $\mathrm{Ki}-67 \mathrm{LI}$ value was $1.8 \%$ in patients who were alive versus $4.7 \%$ in patients who died of disease $(\mathrm{p}=0.01)$.

The mean PFS was 67 (range, 56-77) months for all the patients. The 2-, 5-, and 10-year PFS rates were $85 \%, 49 \%$, and $12 \%$, respectively. The average Ki-67 LI was not associated with PFS. The extent of resection was the only independent prognostic factor that affected PFS in survival analysis.

\section{Discussion}

Ki-67 LI was presented more than two decades ago as a measure of tumor proliferation and because of the need for a prognostic marker that might help clinicians to direct therapy and predict tumor behavior and prognosis [9-18]. Many researchers demonstrated that the Ki-67 expression as a cell division marker has been associated with radioresistance in some cancers.[24] Inhibition of apoptosis could be involved in the complex mechanism of radioresistance with prognostic implications. [25-27] Contrary to these opinions, some researchers claimed that the proliferative cells have relative radiosensitivity compared with non-proliferating cells.[28] A higher Ki-67 LI theoretically defines more proliferative tumors; therefore, it may be expected that patients with higher Ki-67 index might be associated with higher radiosensitivity.[23]

In the current study, we aimed to investigate the possible prognostic relationship between $\mathrm{Ki}-67 \mathrm{LI}$ an the outcomes of adults with grade II glial tumors who were treated with RT. According to our results, age, extent of resection, recurrence or progression, and average Ki-67 LI value were the significant prognostic factors for OS. The average Ki-67 LI value of $\geq 4 \%$ was associated with OS. Patients with a Ki-67 LI value of $\geq 4 \%$ had a poorer OS than patients with a Ki-67 LI value of $<4 \%$. PFS was not affected by Ki-67 LI according to our results. This can be explained by the fact that PFS may have been more influenced by other prognostic factors, such as variability of surgery and variability in the diagnosis of progression.

Despite numerous studies, there are question about the impact of Kİ-67 LI on survival.[7,23,28-32] Some authors have reported correlations between Ki$67 \mathrm{LI}$ and $67 \mathrm{LI}$ and survival. $[7,23,29-7]$ The others did not show an association between Ki-67 LI and survival outcomes. $[30,7]$ These different results can be explained by the variety of techniques that evaluate $\mathrm{Ki}-67 \mathrm{LI}$, subjectivity of interobserver, and heterogeneity of Ki-67 level within the specimen.[12] Some studies included limited number of patients and histologically heterogeneous patient populations. Mckeever et al. reported a strong correlation between low Ki-67 LI and longer survival in 50 patients with WHO grade II astrocytomas.[29] Fisher al. showed in their reserch that mas. 29 - 67 index of $>5 \%$ was predictive of at an average Ki-67 index of $>5 \%$ was predictive of causespecific survival (CSS) and that a maximal Ki-67 index of $>2 \%$ indicated a poorer CSS within the delayed RT subgroup.[23] Similarly, Montine et al. revealed that patients with a Ki-67 LI $\geq 3 \%$ had a poorer survival than patients with a Ki-67 LI of $<3 \%$. [13]

Although most of the studies showed a significant increase in Ki-67 LI with the increasing grade of astrocytomas, $\mathrm{Ki}-67 \mathrm{LI}$ values overlapped in some studies. [31] The Ki-67 LI value of glioblastoma can be as low as [31] The Ki $67 \mathrm{LI}$. those for LGGs, indicating that the Ki-67 LI value cannot be used as a diagnostic measure alone [33] and mus be used in combination with other prognostic factors. According to our results, the other independen prognostic factor that affected OS was recurrence or progression of disease. Our current study revealed that the avoidance of local recurrence or progression after surgery was of comparable relevance to mortality. Local recurrence or progression of disease after surgery can be included as a risk factor predicting decreased 
OS for WHO grade II gliomas. There is a need for prospective studies for the clarification of this issue.

WHO classification of central nervous system tumors updated in 2016, which compose genotypic and phenotypic parameters. The absence of re-classification of tumors according to new version of WHO staging and the retrospective feature of the study were the major limitations of study.

\section{Conclusion}

WHO grade II gliomas are a heterogeneous group of tumors, and there is still significant disagreement between clinicians concerning the optimal treatment. Prognostic factors are important for the prediction of survival and for deciding the most appropriate treatment modality. According to our current study, besides the extent of surgery and recurrence or progression, Ki-67 LI $\geq 4 \%$ was an independent prognostic factor predicting OS. Although Ki-67 LI is a reliable prognostic factor for grade II glial tumors, it should not be used as a diagnostic measure alone, but in combination with other prognostic factors.

Peer-review: Externally peer-reviewed.

Conflict of Interest: The authors declare that there is no conflict of interest.

Funding: This research did not receive any specific grant from funding agencies in the public, commercial, or not-for-profit sectors.

Acknowledgments: We thank the staff of the Departments of Neurosurgery, Neuropathology and Neuroradiology for their support.

Authorship contributions: Concept - G.K., E.Y.E.; Design - G.K., E.Y.E.; Supervision - G.K., E.Y.E., H.S.E.; Materials G.K., E.Y.E., H.S.E., H.O., M.A., M.K., H.B., E.K.; Data collection \&/or processing - G.K., E.Y.E., M.A., M.K., H.B., E.K.; Analysis and/or interpretation - G.K., E.Y.E., H.S.E.; Literature search - G.K., E.Y.E.; Writing - G.K., E.Y.E., H.S.E.; Critical review - G.K., E.Y.E., H.S.E

\section{References}

1. Shaw E, Arusell R, Scheithauer B, O'Fallon J, O’Neill B, Dinapoli R, et al. Prospective randomized trial of lowversus high-dose radiation therapy in adults with supratentorial low-grade glioma: initial report of a North Central Cancer Treatment Group/Radiation Therapy Oncology Group/Eastern Cooperative Oncology Group study JClin Oncol 2002:20(9):2267-76.
2. Pouratian N, Schiff D. Management of low-grade glioma. Curr Neurol Neurosci Rep 2010;10(3):224-31.

3. Keles GE, Lamborn KR, Berger MS. Low-grade hemispheric gliomas in adults: a critical review of extent resection as a factor influencing outcome. J Neurosur

4. Bauman G, Lote K, Larson D, Stalpers L, Leighto C, Fisher B, et al. Pretreatment factors predict overal survival for patients with low-grade glioma: a recursive partitioning analysis. Int J Radiat Oncol Biol Phys 1999;45(4):923-9.

5. Curran WJ Jr, Scott CB, Horton J, Nelson JS, Weinstein AS, Fischbach AJ, et al. Recursive partitioning analysis of prognostic factors in three Radiation Therapy Oncology Group malignant glioma trials. J Natl Cancer Inst 1993;85(9):704-10.

6. Coons SW, Johnson PC, Scheithauer BW, Yates AJ, Pear DK. Improving diagnostic accuracy and interobserver concordance in the classification and grading of primary gliomas. Cancer 1997;79(7):1381-93.

7. Wakimoto H, Aoyagi M, Nakayama T, Nagashima G Yamamoto S, Tamaki M, et al. Prognostic significance of Ki-67 labeling indices obtained using MIB-1 monoclonal antibody in patients with supratentorial astrocytomas. Cancer 1996;77(2):373-80.

8. Lopez F, Belloc F, Lacombe F, Dumain P, Reiffers J, 8ernalities of synthesis of Ki67 an gen during the stimulation of lymphocytes. Cytometry

9. Morimura T, Kitz K, Stein H, Budka H. Determination of proliferative activities in human brain tumor specimens: a comparison of three methods. J Neurooncol

10. Ostertag CB, Volk B, Shibata T, Burger P, Kleihues P. The monoclonal antibody Ki-67 as a marker for proliferating cells in stereotactic biopsies of brain tumours

11. Zuber P, Hamou MF, de Tribolet N. Identification of proliferating cells in human gliomas using the mono(1988;22(2):364-8.

12. Raghavan R, Steart PV, Weller RO. Cell proliferation patterns in the diagnosis of astrocytomas, anaplastic as trocytomas and glioblastoma multiforme: a Ki-67 study Neuropathol Appl Neurobiol 1990;16(2):123-33.

13. Montine TJ, Vandersteenhoven JJ, Aguzzi A, Boyko OB, Dodge RK, Kerns BJ, et al. Prognostic significance of Ki67 proliferation index in supratentorial fibrillary astrocytic neoplasms. Neurosurgery 1994;34(4):674-8.

14. Jaros E, Perry RH, Adam L, Kelly PJ, Crawford PJ, Kalbag RM, et al. Prognostic implications of p53 protein, epidermal growth factor receptor, and Ki-67 labelling in brain tumours. Br J Cancer 1992;66(2):373-85.

15. Torp SH, Helseth E, Dalen A, Unsgaard G. Relationships between Ki-67 labelling index, amplification of the epidermal growth factor receptor gene, and prognosis in human glioblastomas. Acta Neurochir (Wien) 1992:117(3-4):182-6.

16. Onda K, Davis RL, Shibuya M, Wilson CB, Hoshino T. Correlation between the bromodeoxyuridine labeling index and the MIB-1 and Ki-67 proliferating cell indices in cerebral gliomas. Cancer 1994;74(7):1921-6.

17. Kindblom LG, Ahldén M, Meis-Kindblom JM, Stenman G. Immunohistochemical and molecular analysis of p53, MDM2, proliferating cell nuclear antigen and Ki67 in benign and malignant peripheral nerve sheath umours. Virchows Arch 1995;427(1):19-26.

18. Cunningham JM, Kimmel DW, Scheithauer BW, O'Fallon JR, Novotny PJ, Jenkins RB. Analysis of proliferation markers and p53 expression in gliomas of astrocytic origin: relationships and prognostic value. Neurosurg 1997;86(1):121-30

19. Leighton C, Fisher B, Bauman G, Depiero S, Stitt L, MacDonald D, et al. Supratentorial low-grade glioma in adults: an analysis of prognostic factors and timing of radiation. J Clin Oncol 1997;15(4):1294-301.

20. Pignatti F, van den Bent M, Curran D, Debruyne C, Sylvester R, Therasse P, et al; European Organization for Research and Treatment of Cancer Brain Tumor Cooperative Group; European Organization for Research and Treatment of Cancer Radiotherapy Cooperative Group. Prognostic factors for survival in adult patients with cerebral low-grade glioma. J Clin Oncol 2002;20(8):207684.

21. Louis DN, Ohgaki H, Wiestler OD, Cavenee WK, Burger PC, Jouvet A, et al. The 2007 WHO classification of tumours of the central nervous system. Acta Neuropathol 2007;114(2):97-109.

22. Jaros E, Perry RH, Adam L, Kelly PJ, Crawford PJ, Kalbag RM, et al. Prognostic implications of p53 protein, epidermal growth factor receptor, and Ki-67 labelling in brain tumours. Br J Cancer 1992;66(2):373-85.

23. Fisher BJ, Naumova E, Leighton CC, Naumov GN, Kerklviet N, Fortin D, et al. Ki-67: a prognostic factor for low-grade glioma? Int J Radiat Oncol Biol Phys
2002;52(4):996-1001.

24. WillettCG Warland G Cheek R, Coen J, Efird J, Shellito PC, et al. Proliferating cell nuclear antigen and mitotic activity in rectal cancer: predictor of response to preoperative irradiation. J Clin Oncol 1994;12(4):679-82.

25. Symonds H, Krall L, Remington L, Saenz-Robles M, Lowe $S$, Jacks $T$, et al. p53-dependent apoptosis suppresses tumor growth and progression in vivo. Cell 1994;78(4):703-11.

26. Thompson CB. Apoptosis in the pathogenesis and treatment of disease. Science 1995;267(5203):1456-62.

27. Lowe SW, Ruley HE, Jacks T, Housman DE. p53-dependent apoptosis modulates the cytotoxicity of anticancer agents. Cell 1993;74(6):957-67.

28. Little JB. Differential response of rapidly and slowly proliferating human cells to X irradiation. Radiology 1969;93(2):307-13.

29. McKeever PE, Ross DA, Strawderman MS, Brunber JA, Greenberg HS, Junck L. A comparison of the predictive power for survival in gliomas provided by MIB1 , bromodeoxyuridine and proliferating cell nuclear antigen with histopathologic and clinical parameters. Neuropathol Exp Neurol 1997;56(7):798-805.

30. Dirven CM, Koudstaal J, Mooij JJ, Molenaar WM. The proliferative potential of the pilocytic astrocytoma: the relation between MIB-1 labeling and clinical and neuroradiological follow-up. J Neurooncol 1998;37(1):9-16.

31. Hilton DA, Love S, Barber R, Ellison D, Sandeman DR Accumulation of p53 and Ki-67 expression do not predict survival in patients with fibrillary astrocytomas or the response of these tumors to radiotherapy. Neurosurgery 1998;42(4):724-9.

32. Nakamura M, Konishi N, Tsunoda S, Nakase H, Tsuzuki T, Aoki H, et al. Analysis of prognostic and survival factors related to treatment of low-grade astrocytomas in adults. Oncology 2000;58(2):108-16.

33. Johannessen AL, Torp SH. The clinical value of Ki-67/ MIB-1 labeling index in human astrocytomas. Path Oncol Res 2006;12(3):143-7. 